\title{
Olhares e perspectivas sobre os festivais audiovisuais
}

Izabel de Fátima Cruz Melo ${ }^{1}$

Juliana Muylaert Mager²

Tetê Mattos ${ }^{3}$

No final dos anos 1970, quando foi publicado o livro de Miriam Alencar O cinema em festivais e os caminhos do curta-metragem no Brasil (1978), os textos sobre festivais se restringiam a artigos de imprensa e publicações dos próprios eventos como boletins, livros e catálogos (Tavares, 1978; Carrion, 1987). A edição da obra de Alencar, resultado de sua tese de livre-docência, não foi suficiente para modificar o cenário e os festivais permaneceram largamente ignorados pelos estudos de cinema e audiovisual. Nos anos 1990, o crescimento dos festivais de cinema e audiovisual despertaram a atenção da imprensa e provocaram debates, mas foi nos anos 2000 que os primeiros estudos sistemáticos foram realizados, como os diagnósticos setoriais realizados por Antônio Leal e Tetê Mattos $(2007 ; 2011)$ e a pesquisa de mestrado de Izabel Melo que resultou em dissertação defendida em 2009, publicada no livro Cinema é mais que filme (2016). Nesse mesmo período os festivais eram estudados por pesquisadores internacionais, sobretudo, mas não exclusivamente, na Europa (De Valck 2007; Iordanova 2009; Harbord 2009; Wong 2011; Stringer 2001), cujas pesquisas - acrescidas de muitas outras desde então e somadas à articulação em redes e grupos de debates - foram importantes no estabelecimento de bases teóricas e metodológicas para a abordagem dos festivais de cinema e na alteração do lugar desses eventos nos estudos fílmicos.

Em contexto Ibero Americano, a recente organização de dossiês temáticos sobre festivais tem sido importante para a divulgação de pesquisas em espanhol e português, já que grande parte da bibliografia da área está em inglês. São exemplos dessas publicações em periódicos: o número monográfico editado por Aida Vallejo (2014) para a revista Secuencias; o dossiê Encuentros en los márgenes: festivales de cine $y$ documental latinoamericano, organizado por María Paz Peirano e Mariana Amieva (2018) para o periódico Cine Documental; o número especial sobre Festivales de cine en América Latina: Historias y nuevas perspectivas na revista Comunicación y Medios

\footnotetext{
1 Doutora em Meios e Processos Audiovisuais, pela ECA/USP (2018). É professora da UNEB. Pesquisadora Associada da Filmografia Baiana.

Email: izabelc.melo@gmail.com

${ }^{2}$ Pós-doutoranda no Laboratório de História Oral e Imagem da Universidade Federal Fluminense (UFF). Doutora em História pela UFF.

Email: jumuylaert@gmail.com

${ }^{3}$ Doutora pelo Programa de Pós-graduação em Comunicação da UERJ. É professora adjunta da Universidade Federal Fluminense.

Email: tetemattos13@gmail.com
} 
sob a organização de Aida Vallejo e María Paz Peirano (2020); e o dossiê Festivais de cinema e os seus contextos socioculturais com textos reunidos por Aida Vallejo e Tânia Leão (2021) na revista Aniki. Na América Latina, encontramos alguns trabalhos nos anos 1990 e 2000, em sua maioria monográficos (Francia, 1990; Kriger, 2004; Triana-Toribio 2007), mas sobretudo a partir dos anos 2010 (Amieva, 2010, 2018a, 2018b; Campos, 2020; Mestman, Ortega, 2018; Peirano, 2016, 2020) sendo muitos deles referências para as investigações realizadas no Brasil.

Nos anos 2010, os estudos sobre os festivais cinematográficos ganharam espaço no Brasil, valendo mencionar os trabalhos acadêmicos de mestrado (Corrêa, 2021; Rocha, 2015; Cotrim, 2017; Dylan, 2021; Garrett, 2020) e doutorado (Fleck 2013; Mager 2019; Mattos 2018a; Melo 2018; Pires 2019; Silva 2012), além da publicação de artigos (Dylan, 2019; Foster, 2021; Muylaert, 2021; Oliveira, 2016; Pires, 2021; Vieira e Gusmão, 2017; Zanatto, 2021), capítulos (Ikeda, 2018; Mattos, 2013, 2018b, 2021; Melo, 2021; Muylaert e Mattos, 2021, Nogueira, 2020; Vieira Jr., 2018) e livros (Melo, 2016; Cesar, 2020) ${ }^{4}$. Em diálogo com a bibliografia internacional, mas com características próprias, essas publicações representam as primeiras iniciativas de exploração de um campo largamente desconhecido, valendo também citar o trabalho de cartografia dos eventos realizados anualmente por Paulo Corrêa (2016; 2018; 2019; 2020; 2021; 2022), disponibilizados pela Associação Kinoforum. O impulso dos anos 2010 foi fundamental para que nos últimos dois anos um debate mais sistemático sobre os festivais de cinema pudesse se desenvolver a partir da reunião de pesquisadores interessados no tema, tendo como resultado a criação do grupo Festivais de cinema e audiovisual: história, políticas e práticas (CNPq) e a organização do presente dossiê, entre outras iniciativas.

Vivendo um momento de transformação em meio às mudanças provocadas pela pandemia da Covid-19 e pela crise política que vem afetando os investimentos no setor nos últimos anos, diferentes festivais de cinema e audiovisual no Brasil são alvo do olhar de pesquisadores de distintas partes do país no presente dossiê. Os textos enviados reforçam nossa hipótese sobre a prevalência dos trabalhos dedicados a compreender 0 contexto festivaleiro nacional no Brasil. As relações entre os festivais nacionais e outros circuitos regionais e globais são temáticas que aparecem em menor medida. Dividido em dois volumes, nesta edição, o leitor tem acesso à primeira parte do dossiê cujos temas giram em torno do passado e do futuro dos festivais, investindo também no debate sobre a memória desses eventos culturais e seu potencial.

\footnotetext{
${ }^{4}$ Embora tenhamos mencionado uma quantidade significativa de trabalhos, não é nossa intenção fazer aqui um levantamento exaustivo, mas sim apontar a multiplicidade de abordagens e perspectivas no campo dos estudos de festivais, o que torna esta listagem instável e provisória, sendo assim sujeita a novos acréscimos.
} 
Questões metodológicas e teóricas atravessam todos os trabalhos, assumindo o centro no artigo El estudio de festivales de cine: aproximaciones metodológicas, de María Paz e Aida Vallejo. Ao se debruçar sobre os Film Festivals Studies, as autoras dedicam um olhar mais detido ao panorama de pesquisas e publicações ibero americanas, a partir de inquietações tais como a própria definição do festival como um objeto de pesquisa, a importância dos arquivos, tanto para festivais iniciados em décadas anteriores quanto para os contemporâneos, além do uso da cartografia, etnografia, estatística e análise fílmica atravessada pelas questões curatoriais, como metodologias que permitem o aprofundamento dos estudos de festivais sob perspectivas renovadas e instigantes.

No artigo O Festival de Cinema Científico-Educativo (1954): Jean Painlevé no Brasil, Rafael Zanatto apresenta ao leitor uma visada histórica desse evento que integrou a programação do I Festival Internacional de Cinema do Brasil, realizado em São Paulo, em 1954, em consonância com os circuitos festivaleiros europeus, então em formação. Zanatto destaca a presença de Jean Painlevé no Brasil na ocasião e a relação com o cenário científico e cultural brasileiro, discutindo o impacto dessa seção do evento para o cinema científico no país. Resultado de pesquisa documental em arquivos, o texto de Zanatto traz importantes elementos para o entendimento das primeiras experiências festivaleiras no país e o debate sobre o complexo perfil do evento de 1954.

Também dedicado ao período dos anos 1950, Um festival para as chanchadas? As conexões entre o Festival Cinematográfico do Distrito Federal e as comédias musicais (1953-1959), de Carlos Eduardo Pinto de Pinto, aborda a trajetória de outro evento do período. Diferente do festival realizado em São Paulo, o Festival Cinematográfico do DF era sediado no Rio de Janeiro, então capital do país, e tem recebido pouca atenção nos estudos realizados sobre os anos 1950, além de algumas menções de passagem. Também apoiado em pesquisa documental, com destaque para as fontes da imprensa, o texto se volta para a análise da recepção das chanchadas no evento e discutindo a relação do cinema e do evento com a construção do imaginário da cidade carioca.

O artigo de Emerson Dylan e Luis Ferla nos leva para São Paulo em meados dos anos 1970, momento de criação da Mostra Internacional de Cinema São Paulo, evento criado em 1977 no Museu de Arte de São Paulo (MASP). Ainda em atividade, a Mostra é um dos festivais mais longevos do país, o trabalho de Dylan e Ferla traz uma metodologia inovadora no estudo de festivais no Brasil, utilizando o georreferenciamento para analisar a presença do festival na capital paulista em suas primeiras edições, no período em que esteve ligada ao MASP. A relação entre território e cinefilia é analisada 
pelos autores, integrando tempo, espaço e sociabilidade como categorias fundamentais para a reflexão histórica sobre os festivais cinematográficos.

Os três artigos com ênfase nos anos 1950 e 1970 dão a ver relações complexas traçadas entre os festivais, as cidades e o campo cultural, político e científico, lembrando a importância da preservação dos acervos e o incentivo a novas investigações, relevantes para o melhor entendimento das dinâmicas históricas dos festivais brasileiros e seu impacto no presente. Nessa perspectiva, o artigo Festivais e mostras de cinema e audiovisual na Bahia: entre trajetórias e práticas de formação cultural, de Milene Gusmão e Tamara Cotrim, faz um levantamento a respeito dos festivais e mostras no estado da Bahia, observando tanto do ponto de vista histórico, quanto do processo de criação de um circuito de festivais no interior a partir dos anos 2000. Assim como no artigo anterior, aqui também as políticas públicas de fomento ao cinema e audiovisual tem centralidade nessa expansão de modo mais sistemático, permitindo a continuidade e desdobramento das práticas sociais relacionadas ao cinema.

Estabelecendo uma ponte entre o debate sobre a história e os textos já voltados para o contexto atual dos festivais, o artigo Memória e ação com o CachoeiraDoc: um festival de cinema com e como política pública, de autoria de Amaranta Cesar e Leonardo Costa, trata do festival a partir de uma mirada interna, ou seja, dos seus organizadores, construindo um prisma que articula a sua relação com a universidade, as políticas públicas de fomento e seu posicionamento contra hegemônico no circuito de festivais no Brasil. Segundo os autores, essas características, geraram um festival com forte viés formativo, colaborando para o reposicionamento político no campo cinematográfico, por salientar ao lado de outras iniciativas como o Fórum.doc, "relações socioculturais não orientadas por princípios comerciais". Cesar e Costa afirmam que o evento de Cachoeira buscou novos caminhos que ultrapassassem o cânone, trazendo debates com aderência direta a questões não apenas da história do cinema, mas que permitissem o comprometimento do cinema e suas ações na vida social.

O artigo COVID-19 e os impactos na produção de festivais de cinema brasileiros: estratégias cotidianas para migração online, de Eveline Stella de Araújo e Sabrina Demozzi, busca compreender as condições e características dos festivais de cinema no contexto da pandemia de Covid-19 articulando referencial teórico com pesquisa de caráter exploratório realizada pelos autores, utilizando como método a aplicação de questionário, assim como a consulta de dados estatísticos e georreferenciados disponíveis na Internet. as formas de adaptação para a realização dos festivais no formato online de exibição, os modos de participação do público no formato online, e os desafios e ações bem-sucedidas no contexto digital de cinema online. 
O artigo Curta Taquary: o processo de reinvenção de um festival de cinema durante a pandemia da Covid-19, de autoria de Edsamy Dantas da Silva, Cláudio Roberto de Araújo Bezerra, Aline Maria Grego Lins e Alexandre Figueirôa Ferreira aborda um estudo de caso do festival realizado no interior de Pernambuco, o Curta Taquary. Os autores focam no estudo das estratégias de adaptação do festival, realizado em abril de 2020. O festival foi um dos primeiros a migrar para o formato online. Com foco nas práticas de realização de um festival, os autores analisam como o evento se organizou frente às exigências de realização no ambiente online, destacando as estratégias de programação, de exibição online, a dinâmica de produção do festival e as ações de divulgação e mobilização do público. A partir desta experiência, os autores refletem sobre o futuro dos festivais de cinema pós-pandemia.

Em Plataformização dos festivais de cinema e audiovisual: a experiência do MixBrasil, os autores João Massarolo, Dario Mesquita, André Fischer e Cláudia Erthal abordam o fenômeno da plataformização das práticas culturais em festivais de cinema e audiovisual no contexto brasileiro realizados durante a pandemia de Covid-19. $\mathrm{Na}$ análise, a experiência do MixBrasil ganha destaque ao utilizar recursos de plataformas para apresentação de outras expressões artísticas - teatro, performance e shows musicais - além do cinema. Sobre o processo de plataformização, os autores concluem que "além da entrega de conteúdo online, se apresenta como uma importante ferramenta para a captura da atenção do espectador, colhendo dados estratégicos para a curadoria e a realização de diferentes atividades para o fortalecimento de público em torno de festivais".

Por último, na resenha Festivais de documentário em perspectiva sociohistórica, Juliana Muylaert e Bianca Pires apresentam o livro Documentary Film Festival v.1, organizado por Aida Vallejo e Erza Winton. Segundo Muylaert e Pires, embora o livro concentre suas atenções especificamente para os festivais voltados ao documentário, no que destacam seu caráter pioneiro, aponta para caminhos de reflexão e pesquisa que podem ser apropriados para os estudos de festivais de forma mais ampla. Segundo a resenha, o livro é organizado em 3 sessões que se dividem em 4 blocos temáticos articulando questões que abordam de modos diversos as fontes, métodos, história da cultura e relevância política dos festivais em diversos lugares do mundo. Desta maneira, podemos ter uma visão ampla dos debates propostos pelos organizadores e autores, contribuindo para a recepção da obra no contexto brasileiro.

Esperamos que essa breve apresentação sobre os festivais audiovisuais e seus estudos sirva como um convite à leitura dos mais recentes frutos desse novo campo de 
reflexão reunidos a seguir na primeira parte do dossiê Festivais e Mostras Audiovisuais - olhares e perspectivas.

\section{Referências:}

ALENCAR, Miriam. O cinema em festivais e os caminhos do curta-metragem no Brasil. Rio de Janeiro: Artenova, 1978.

AMIEVA, Mariana. "¿Cómo el Uruguay no hay? La participación del Festival de Cine Documental y Experimental del SODRE en las redes de festivales y sus particularidades". Cine Documental, n. 18, 2018 a, p. 8-36.

AMIEVA, Mariana. El Festival Internacional de Cine Documental y Experimental del SODRE: las voces del documental y un espacio de encuentro para el cine latinoamericano y nacional. In: TORELLO, Georgina (Org.). Uruguay se filma: prácticas documentales (1920-1990). Montevidéu: Irrupiciones, 2018b. p 85-113.

AMIEVA, Mariana; PEIRANO, Maria Paz. (Org.). "Dossier Encuentro en los márgenes: festivales de cine y documental latinoamericano". CineDocumental. n 18. 2018.

CAMPOS, Minerva. 2020. "Tensiones en el circuito cinematográfico internacional: modelo para el estudio de los festivales latinoamericanos". Comunicación y Medios, n. 42, p. 72-84.

CESAR, Amaranta et al. (Org.) Desaguar em cinema: documentário, memória e ação com o CachoeiraDoc. Salvador: Edufba, 2020.

CARRION, Luiz Carlos. Festival do Cinema Brasileiro de Gramado: levantamento dos seus primeiros 14 anos. Porto Alegre: Tchê!, 1987.

CORRÊA, Paulo Luz. Festivais de cinema e a Internet: uma breve análise por meio do formato de submissão de filmes. São Paulo, 2016. Disponível em: <https://linktr.ee/estudosfestivais>.

CORRÊA, Paulo Luz. Os Festivais Audiovisuais em 2017: Geografia e Virtualização. São Paulo, 2018. Disponível em: <https://linktr.ee/estudosfestivais>.

CORRÊA, Paulo Luz. Os Festivais/ Mostras Audiovisuais em 2018: Geografia e Virtualização. São Paulo, 2019. Disponível em: <https://linktr.ee/estudosfestivais>.

CORRÊA, Paulo Luz. Os Festivais/ Mostras Audiovisuais em 2019: Geografia e Virtualização. São Paulo, 2020. Disponível em: <https://linktr.ee/estudosfestivais>.

CORRÊA, Paulo Luz. Panorama dos Festivais/Mostras Audiovisuais Brasileiros edição 2020. São Paulo, 2021. Disponível em: <https://linktr.ee/estudosfestivais>.

CORRÊA, Paulo Vitor Luz. Panorama dos Festivais/Mostras Audiovisuais Brasileiros e Sessão Lei Aldir Blanc - edição 2021. São Paulo, 2022. Disponível em: $<$ https://linktr.ee/estudosfestivais>. 
CORRÊA, Paulo Vitor Luz. Sol, praia, badalação e filmes: o envolvimento do Instituto Nacional de Cinema com os festivais de cinema a partir de um estudo de caso dos eventos da Baixada Santista (1970-1974). 2021. Dissertação (Mestrado em Comunicação). Universidade Anhembi Morumbi, São Paulo.

COTRIM, Tamara Chequer. Festivais e mostras de cinema na Bahia contemporânea: memória e processos de formação cultural. 2017. Dissertação (mestrado) - Universidade Estadual do Sudoeste da Bahia, Programa de PósGraduação em Memória: Linguagens e Sociedade, Vitória da Conquista. Disponível em: $<$ http://www2.uesb.br/ppg/ppgmls/wp-content/uploads/2017/07/Dissert.-TamaraChequer-Cotrim.pdf $>$.

DE VALCK, Marijke. Film festivals: from european geopolitics to global cinephilia. Amsterdam: Amsterdam University Press, 2007, 276 p.

DE VALCK, Marikje; KREDELL, Brendan e LOIST, Skadi (Orgs). Film Festivals History, theory, method, practice. London and New York: Routledge, 2016, 256 p.

DYLAN, Emerson. "O Festival e a cidade. A Mostra Internacional de Cinema de São Paulo como um espaço de sociabilidade na capital paulista". CSOnline, n. 29. 2019, p. 33-44.

DYLAN, Emerson. Território da cinefilia: a Mostra Internacional de Cinema e a cidade de São Paulo (1977-1983). 2021. Dissertação (Mestrado em História) Universidade Federal de São Paulo, Escola de Filosofia, Letras e Ciências Humanas, Guarulhos, São Paulo.

FLECK, João Pedro dos Santos. Consumo fanático: uma análise exploratória nos festivais de cinema fantástico (Doutorado em Administração) - Programa de pósgraduação em administração, UFRGS, Porto Alegre.

FOSTER, Lila. "Matizes da cultura jovem: imagens e imaginários em torno do Festival de Cinema Amador JB/Mesbla". Estudos históricos, n. 34 (72), Jan-Abr 2021, p. 30-53. https://doi.org/10.1590/S2178-149420210103.

FRANCIA, A. 1990. Nuevo Cine Latinoamericano en Viña del Mar. Santiago de Chile: CESOC.

GARRETT, Adriano. A curadoria em cinema no Brasil contemporâneo: festivais de cinema e o caso da Mostra Aurora (2008-2012). 2020. 176 f. Dissertação (Mestrado em Comunicação), Universidade Anhembi Morumbi, São Paulo.

IKEDA, Marcelo. "Novos desafios na curadoria e programação no cinema brasileiro do século XXI". In: MENOTTI, Gabriel. (Org.) Curadoria, cinema e outros modos de dar a ver. Vitória, EDUFES, 2018, p. 107-116.

IORDANOVA, Dina; Rhyne, Ragan (Orgs.). Film Festival Yearbook 1: The Festival Circuit. St Andrews Film Studies, 2009, 225 p.

KRIEGER, Clara. "Inolvidables jornadas vivió Mar del Plata. Perón junto a las estrellas". Archivos de la Filmoteca, n. 46, 2004, p. 118-131.

LEAL, Antonio; MATTOS, Tetê. Festivais audiovisuais: diagnóstico setorial 2007 indicadores 2006. Rio de Janeiro: Fórum dos Festivais / MinC/SAv, 2007. 89 p. 
LEAL, Antonio; MATTOS, Tetê. Painel setorial dos festivais audiovisuais indicadores 2007 - 2008 - 2009. Rio de Janeiro: Fórum dos Festivais / MinC/SAv, 2011. $63 \mathrm{p}$.

LEÃO, Tânia; VALLEJO, Aida. (Org.) "Festivais de cinema e os seus contextos socioculturais". Aniki. v. 8. n. 1. 2021.

MAGER, Juliana Muylaert. É tudo verdade? cinema, memória e usos públicos da história. 2019. 221 f. Tese (Doutorado em História). Instituto de História, Universidade Federal Fluminense, Niterói, Rio de Janeiro.

MATTOS, Tetê. "Festivais pra quê? Um estudo crítico sobre festivais audiovisuais brasileiros". In: BAMBA, Mahomed. A recepção cinematográfica: teoria e estudos de caso. Salvador: EDUFBA, 2013. p. 117-131.

MATTOS, Tetê. O Festival do Rio e as configurações da cidade do Rio de Janeiro. 2018a. Tese (Doutorado em Comunicação), Faculdade de Comunicação Social, Universidade do Estado do Rio de Janeiro, Rio de Janeiro.

MATTOS, Tetê. "O Festival do Rio e a construção do imaginário da cidade". In: MENOTTI, Gabriel. (Org.) Curadoria, cinema e outros modos de dar a ver. Vitória, EDUFES, 2018b, p. 177-188.

MATTOS, Tetê. "Festivais de cinema no Brasil - uma abordagem feminina". In: TEDESCO, Marina Cavalcanti (Org.) Trabalhadoras do cinema brasileiro: mulheres muito além da direção. Rio de Janeiro: NAU Editora, 2021, p. 179-200.

MELO, Izabel de Fátima Cruz. "Cinema é mais que filme": uma história das Jornadas de Cinema da Bahia (1972-1978). Salvador: EDUNEB. 2016.

MELO, Izabel de Fátima Cruz. Cinema, circuitos culturais e espaços formativos: sociabilidades e ambiência na Bahia (1968-1978). 2018. 224 f. Tese (Doutorado em Meios e Processos Audiovisuais) - Escola de Comunicação e Artes, Universidade de São Paulo, São Paulo.

MELO, Izabel de Fátima Cruz Melo. "Festivais, mostras e cinemas negros na Bahia: uma história em curso". In: SILVA, Mile et al (Org). Cinema Negro Baiano. Salvador: Emoriô, 2021, p. 121-133.

MESTMAN, Mariano; ORTEGA, María Luisa. "Cruces de miradas en la transición del cine documental. John Grierson en Sudamérica". CineDocumental, n. 18, 2018, p. 172-204.

MUYLAERT, Juliana e MATTOS, Tetê. "Festivais audiovisuais no Brasil: um debate a partir de duas trajetórias de pesquisa,. In: AMÂNCIO, Cardes et al. (Orgs). Cinema: afetos e territórios. Belo Horizonte: LED, 2021. p. 96-118.

PEIRANO, María Paz. "Mapping histories and archiving ephemeral landscapes: strategies and challenges for researching small film festivals". Studies in European Cinema, v. 17, n. 2, 2020, p. 170-184. 
MUYLAERT, Juliana. "A Contribuição do Festival É Tudo Verdade ao Cânone do Documentário Brasileiro". Aniki, v. 8, n. 1, 2021, p. 219-244. (Festivais de cinema e os seus contextos socioculturais). DOI: https://doi.org/10.14591/aniki.v8n1.718

NOGUEIRA, Cyntia. Walter da Silveira e o I Festival de Cinema da Bahia (1951). In: NOGUEIRA, Cyntia. (Org.) Walter da Silveira e o cinema moderno no Brasil. Salvador: Edufba: 2020, p. 457-466.

OLIVEIRA, Janaína. "Descolonizando telas: o FESPACO e os primeiros tempos do cinema africano". Odeere: revista do programa de pós-graduação em Relações Etnicas e Contemporaneidade - UESB, ano 1, n. 1, v.1, jan.- jun. 2016, p. 50-74.

PEIRANO, María Paz. "Pursuing, resembling, and contesting the global: the emergence of Chilean film festivals". New Review of Film and Television Studies, n. 14 (1), 2016, p. 112-131.

PEIRANO, María Paz. "Mapping histories and archiving ephemeral landscapes: strategies and challenges to research film festivals". Studies in European Cinema, n. $17: 2,2020$, p. $170-184$

PEIRANO, María Paz; VAllejo, Aida. (Org.). "Editorial Festivales de cine en América Latina: Historia y nuevas perspectivas". Comunicación y Medios, n. 42. 2020.

PIRES, Bianca Salles. A formação de públicos cinéfilos: Circuitos paralelos, Museus e Festivais Internacionais. 2019. Tese (Doutorado). Programa de PósGraduação em Sociologia e Antropologia, Universidade Federal do Rio de Janeiro, Rio de Janeiro.

PIRES, Bianca Salles. "La circulación del cine documental en tiempos de pandemia: experiencias de festivales en línea en Brasil y México". O público e o Privado, v. 19, n. 38, jan./abr. 2021. Dossiê Artes em tempos de pandemia.

ROCHA, Flavio Rogerio. Super Festivais do GRIFE: produção, circulação e formação de cineastas no Super8 brasileiro (1973-1983). 2015. Dissertação (Mestrado em Imagem e Som) - Universidade Federal de São Carlos, São Carlos. Disponível em: <https://repositorio.ufscar.br/handle/ufscar/10471.>

SILVA, Marcos. Territórios do desejo: performance, territorialidade e cinema no Festival Mix Brasil da Diversidade Sexual. 2012. 370 f. Tese (Doutorado em Antropologia Social) - Centro de Filosofia e Ciências Humanas, Universidade Federal de Santa Catarina.

TAVARES, Bráulio. O curta-metragem brasileiro e as Jornadas de Salvador. Salvador: Gráfica do Banco Econômico. 1978.

TRIANA-TORIBIO, Nuria. "El festival de los cinéfilos transnacionales: Festival Cinematográfico Internacional de la República Argentina en Mar del Plata, 19591970". Secuencias: Revista de Historia del Cine, n. 25, 2007, p. 25-45.

VALLEJO, Aida (Org.). "Número dedicado a Festivales Cinematográficos". Secuencias, n. 39, 2014. 
VIEIRA, Mariella Pitombo; GUSMÃO, Milene. "O mercado audiovisual brasileiro, o circuito alternativo de exibição, as mostras e festivais de cinema na Bahia contemporânea". Ciências Sociais Unisinos, São Leopoldo, v. 53, n. 1, 2017, p. 36-45.

VIEIRA JR, Erly. "Por um cinema com arestas: a experiência da Mostra Corsária no Festival de Cinema de Vitória (2012-2016)". In: MENOTTI, Gabriel. (Org.) Curadoria, cinema e outros modos de dar a ver. Vitória, EDUFES, 2018, p. 117-132.

WONG, Cindy Hint-Yuk. Film Festivals. Culture, people and power on the global screen. London: Rutgers University Press. 2011, 332 p.

ZANATTO, Rafael Morato. "O I Festival Internacional de Cinema do Brasil (1954)". Aniki, v. 8, n. 1, 2021, p. 101-130. 